\title{
Integrative roles of transforming growth factor- $\alpha$ in the cytoprotection mechanisms of gastric mucosal injury
} Takashi Kosone ${ }^{1}$, Hitoshi Takagi ${ }^{1}$, Satoru Kakizaki ${ }^{1}$, Naondo Sohara1, Norio Horiguchi ${ }^{1}$, Ken Sato ${ }^{1}$, Masashi Yoneda ${ }^{3}$, Toshiyuki Takeuchi*2 and Masatomo Mori ${ }^{1}$

Address: ${ }^{1}$ Department of Medicine and Molecular Science, Gunma University Graduate School of Medicine, Maebashi 371-8511, Japan, 2Department of Molecular Medicine, the Institute for Molecular and Cellular Regulation, Gunma University, Maebashi 371-8512, Japan and ${ }^{3}$ Department of Gastroenterology, Dokkyo University School of Medicine, Tochigi 321-0293, Japan

Email: Takashi Kosone - tkosone@med.gunma-u.ac.jp; Hitoshi Takagi - htakagi@med.gunma-u.ac.jp; Satoru Kakizaki - horiguti@med.gunmau.ac.jp; Naondo Sohara - sohara@showa.gunma-u.ac.jp; Norio Horiguchi - kakizaki@showa.gunma-u.ac.jp; Ken Sato - satoken@showa.gunmau.ac.jp; Masashi Yoneda - yoneda@dokkyomed.ac.jp; Toshiyuki Takeuchi* - tstake@showa.gunma-u.ac.jp; Masatomo Mori - mmori@med.gunma-u.ac.jp

* Corresponding author

Published: 0I August 2006

BMC Gastroenterology 2006, 6:22 doi:10.1 186/147I-230X-6-22
Received: 22 December 2005

Accepted: 0I August 2006

This article is available from: http://www.biomedcentral.com/I47I-230X/6/22

(C) 2006 Kosone et al; licensee BioMed Central Ltd.

This is an Open Access article distributed under the terms of the Creative Commons Attribution License (http://creativecommons.org/licenses/by/2.0), which permits unrestricted use, distribution, and reproduction in any medium, provided the original work is properly cited.

\begin{abstract}
Background: Transforming growth factor $\alpha$ (TGF $\alpha$ ) protects against gastric mucosal injury and facilitates wound healing. However, its overexpression is known to induce hypertrophic gastropathy resembling Menetrier's disease in transgenic (TG) mice on an FVB background, as one of the authors reported previously. We studied another TGF $\alpha$-expressing mouse line on a CDI background, whose gastric mucosa appears normal. Since this TG mouse had a strong resistance to ethanol-induced gastric injury, we considered the long-term effect of TGF $\alpha$ on several gastric protection mechanisms.

Methods: TGF $\alpha$-expressing transgenic (TG) mouse lines bearing human TGF $\alpha$ cDNA under the control of the mouse metallothionein gene I promoter were generated on a CDI mouse background, and analyzed their ethanol injury-resistant phenotypes produced by TGF $\alpha$.

Results: In the TG mucosa, blood flow was well maintained after ethanol injury. Further, neural and inducible types of NO synthases were consistently and widely expressed in the TG mucosa, compared with the limited distribution of neural type NO synthase in the luminal pit region of the wild-type (WT) mucosa. COX-2 and its upstream transcription factor NfkB were constitutively elevated in the TG mucosa even before ethanol administration, whereas they were induced in the same region of the WT mucosa only after ethanol injury. Two anti-apoptotic proteins, HSP70 and $\mathrm{BCl}-2$, were upregulated in the TG mucosa even before ethanol administration, while they were not expressed in the WT mucosa before the injury. Furthermore, pro-caspase 3 activation was inhibited in the TG mucosa, while it was converted to the active form in the WT mucosa following ethanol administration.
\end{abstract}

Conclusion: We conclude that TGF $\alpha$ maintains the gastric mucosal defense against gastric injury by integrating other cytoprotective mechanisms. 


\section{Background}

Ethanol has long been used to generate a hemorrhagic gastric mucosal injury in rodents [1]. With oral administration of absolute or hydrochloric acid-acidified ethanol, extensive hemorrhagic lesions can be produced in the gastric mucosa. This experimental gastric injury model has been frequently used for gastric mucosal protection and restitution studies. Indeed, a number of cytoprotective compounds have been tested to evaluate their potency in resisting gastric injury, including gastrointestinal hormones, growth factors, prostaglandins, bioactive amines, and mild irritants such as capsaicin [2-5]. Among these compounds, epidermal growth factor (EGF) family growth factors, notably transforming growth factor $\alpha$ (TGF $\alpha$ ), have been reported as potent cytoprotective compounds against ethanol-, acetic acid-, or aspirin-induced gastric injury $[2,4]$.

TGF $\alpha$ was expressed in the rat gastric mucosa after oral administration of acidified taurocholate or hydrochloric acid, suggesting its reparative role in gastric injury [6]. TGF $\alpha$ given intraperitoneally protected against ethanolinduced gastric injury with a significant increase in adherent gastric mucin in rats [7]. The cytoprotective function of TGF $\alpha$ appeared to be mediated by activation of phospholipase C- $\gamma 1$, but not by prostaglandins, and was independent of the anti-secretory effect of TGF $\alpha$ [7]. On the other hand, prostaglandins and their synthetic enzyme, cyclooxygenase (COX), have long been proposed as cytoprotective factors against gastric injury $[5,8]$. EGF has been shown to express an inducible COX isoform, COX-2, in the RGM1 rat gastric mucosal cell line through an ERK MAP kinase pathway [9] and in Swiss 3T3 fibloblasts, especially by co-stimulation with gastrin [10]. Furthermore, COX-2 expression by heparin-binding EGF-like growth factor, a member of the EGF family growth factors, was blocked by a specific EGF receptor (EGF-R) inhibitor in the rat gastric mucosa [11]. Thus, the EGF-R signal appears to mediate COX-2 induction in the gastric mucosa.

The most important cytoprotective mechanisms include gastric mucosal blood flow. EGF and TGF $\alpha$ have been shown to exert cytoprotective effects via stimulation of capsaicin-sensitive neurons with release of calcitonin gene-related peptide (CGRP) and nitric oxide (NO) in rats exposed to orogastric ethanol administration, resulting in an increase in gastric mucosal blood flow $[11,12]$. In contrast, Konturek et al. minimized the role of the CGRPdependent increase in gastric blood flow by demonstrating that the administration of NO-releasing aspirin offered protection against absolute ethanol-induced gastric injury even in capsaicin-denervated rats, resulting in the upregulation of heat shock protein 70 (HSP70) expression and attenuation of the oxidative injury by strong upregulation of antioxidative genes such as zinc copper superoxide dismutase (SOD) and glutathione peroxidase [13].

TGF $\alpha$ was immunostained predominantly in GSM cells along the gastric pit in humans [14], intensively in gastric surface mucosal (GSM) cells over the proliferative zone and weakly along the glandular region under the proliferative zone in rats [15], and markedly along the mucous neck cell region in FVB/N strain mice [16]. On the other hand, EGF-R was immunostained in GSM cells lining the foveolar pit and mucous neck cell region to the lower glandular region in humans [17]. In rats, EGF-R was localized at the top-pit region and in the chief cell clusters at the bottom of the gastric glands [15]. Although TGF $\alpha$ is known to induce cell proliferation in primary-cultured rat gastric mucosal cells [18], and hyperplastic proliferation in the mucosa on the TGFo-expressing transgenic (TG) mouse $[19,20]$, the distribution of TGFo and EGF-R in terminally differentiated gastric mucosal cells suggests that TGF $\alpha$ exerts non-proliferative functions including antiapoptotic effects and gastric epithelial barrier formation in an autocrine/paracrine manner. For example, TGF $\alpha$ inhibited apoptosis of a mouse gastric mucosal cell line, GSM06, by expressing anti-apoptotic Bcl-2 family proteins through an NF-KB-dependent pathway [21]. Gastric apical and basolateral EGF-R has been shown to induce a decrease in paracellular permeability to acid for the protection of glandular cells in an acidic environment $[18,22]$. Thus, TGF $\alpha$ exerts both proliferative and nonproliferative effects on gastric mucosal functions, and these diverse TGF $\alpha$ effects should be re-evaluated, at least in terms of whether their results are derived from shortterm treatment using culture cell lines or from long-term expression using TGF $\alpha$-transgene-expressing animals.

A decade ago, one of the authors, $\mathrm{H}$. Takagi, generated TGF $\alpha$-expressing TG mouse lines under the control of the metallothionein gene promoter, and one of these lines (MT100) exhibited hypertrophic gastropathy resembling Menetrier's disease, as similarly shown by other investigators $[19,20]$. In contrast, another TG line (MT42) displayed a normal-appearing gastric mucosa, although TGF $\alpha$ transgene was expressed to a similar extent in both TG lines [20]. Since the MT42 line displayed a surprising level of resistance to ethanol-induced injury to the gastric mucosa, we considered that it could be useful for exploring the non-proliferative effects of TGF $\alpha$ such as mucosal resistance to ethanol injury. In the present study, we investigated the long-term effects of TGF $\alpha$ on ethanol-induced gastric injury by analyzing changes in cytoprotective and anti-apoptotic regulatory factors, including gastric blood flow, NO synthase, COX-2, and apoptosis-associated proteins such as HSP70, Bcl-2, and caspase 3. 


\section{Methods \\ TGF $\alpha$-expressing transgenic mouse and ethanol-induced gastric injury}

TGF $\alpha$-expressing transgenic (TG) mouse lines bearing human TGF $\alpha$ cDNA under the control of the mouse metallothionein gene I promoter were generated on a CD1 or FVB mouse background, as described previously [20]. One of the TG lines, MT100 on an FVB mouse background, displayed hypertrophic gastropathy resembling Menetrier's disease [20], whereas the other line, MT42 on a CD1 mouse background, displayed a normal-appearing gastric mucosa. The phenotype of the TGF $\alpha$-TG mouse appeared to depend on the mouse strain, because both the MT100 and MT42 lines expressed a similar level of the TGF $\alpha$ transgene in the stomach [20]. In the present study, we used the MT42 line of TGF $\alpha$-expressing TG male mice and CD1 wild type (WT) male mice at ages 6 to 8 weeks. The animals were maintained under controlled light (7:00 AM to 7:00 PM) with food and water provided ad libitum.

The mice, weighing 30-35 g, were fasted for $24 \mathrm{~h}$ before the experiment but were allowed free access to water. All experimental procedures affecting the mice were approved by the Animal Care and Use Review Committee at the Gunma University. The mice were then given orogastric acidified ethanol $(100 \mu \mathrm{l} ; 60 \%$ ethanol in 0.15 $\mathrm{mol} / \mathrm{L} \mathrm{HCl}$ ). Three, six, and twelve hours after the acidified ethanol administration the mice were sacrificed for the evaluation of gastric injury and immunohistochemical analyses, and for RNA and protein extraction for real time PCR, Northern and Western blot analyses.

\section{Physiological studies}

Gastric acid secretion was measured as described previously [20,23]. Briefly, WT and TG mice were fasted for $3 \mathrm{~h}$ and then anesthetized with ether. After the incision of abdominal wall, the pyrolus was ligated, and the incision was sutured. The gastric fluid was collected $4 \mathrm{~h}$ after the pyrolus ligation. For maximal acid output, acid secretion was stimulated by injecting pentagastrin subcutaneously (500 $\mu \mathrm{g} / \mathrm{kg}$ body weight). The gastric fluid was titrated with $0.1 \mathrm{~N} \mathrm{NaOH}$ to $\mathrm{pH} 7.0$ using a microtitrator.

Gastric mucosal blood flow was measured with a laser Doppler flowmeter (model SFA211, Advance Co., Tokyo) by placing a probe on the surface of the gastric mucosa, as described previously [24]. The flow signal was monitored with the MacLab recording program. The blood flow was expressed relative to the basal level.

\section{Morphological studies}

The thickness of the gastric mucosa was measured from the highest part to the bottom of the gland with a micrometer. Similarly, the gastric injury lesions were measured (width and longitude) with a micrometer to calculate the injured area.

For immunostaining, we obtained antibodies as follows. Polyclonal antibody to $\mathrm{H}^{+} / \mathrm{K}^{+}$-ATPase was obtained by injecting rabbit parietal cell-microsomal fractions into mice [25]. Rabbit polyclonal antibody to metallothionein was a kind gift from Dr. Nagamine, Gunma University School of Health Sciences [26]. We purchased antibodies as follows: rabbit polyclonal antibody to TGF $\alpha$, rabbit polyclonal antibody to EGF-R, goat polyclonal antibody to COX-2, rabbit polyclonal antibody to $\mathrm{NF \kappa B}$, and mouse monoclonal antibody to nNOS and iNOS from Santa Cruz Biotech. (Santa Cruz, CA); mouse monoclonal antibody to proliferative-cell nuclear antigen (PCNA) from Zymed Lab. (South San Francisco, CA); sheep antibody to human pepsinogen II from BioPur AB (Bubendorf, Switzerland), which also reacts to mouse pepsinogen; rabbit polyclonal antibody to HSP70 from Stressgen Biotech. (Victoria, BC, Canada); and mouse monoclonal antibody to Bcl-2 from BD Biosciences (San Diego, CA).

For horseradish peroxidase (HRP)-catalyzing immunohistochemical staining, minced stomachs were fixed in neutralized $10 \%$ formalin at $4{ }^{\circ} \mathrm{C}$ for $24 \mathrm{~h}$, and was then embedded in paraffin for microtome sectioning. The deparaffinized tissue sections were rehydrated and incubated in 3\% hydrogen peroxide solution to inhibit endogenous peroxidase activity. Then the sections were incubated with a first antibody described above with an appropriate dilution at room temperature for $30 \mathrm{~min}$. A secondary biotinylated antibody was selected based on the first antibody-producing animal species, and was then used with HRP-conjugated streptavidin. The HRP reaction was performed with 3-amino-9-ethyl-carbazole and hydrogen peroxide according to the instructions supplied with the streptavidin-biotin staining Vectastatin Elite Kit (Vectors Laboratories, Burlingame, CA). Positive stainings appeared brown in color.

For immunofluorescent staining, minced stomachs were fixed in $4 \%$ paraformaldehyde in $0.1 \mathrm{M}$ phosphate buffer, $\mathrm{pH} 7.4$ at $4{ }^{\circ} \mathrm{C}$ for $24 \mathrm{~h}$. Small pieces of minced tissue underwent saccharose replacement and were embedded in OCT-compound in preparation for a frozen section using a microtome. For the primary immunoreaction, sliced sections were probed with a first antibody, and were then incubated either with indodicarbocyanide (Cy3)conjugated affinity-purified donkey anti-rabbit, antimouse IgG (Jackson ImmunoResearch, West Grove, PA), or fluorescein isothiocyanate (FITC)-labeled anti-rabbit IgG (Jackson ImmunoResearch), as a secondary antibody. The secondary antibody IgG was selected based on the species on which the first antibody was raised. 
In situ detection of apoptotic cells was performed using the In Situ Apoptosis Detection Kit (TAKARA BIO INC. Tokyo, Japan). The kit contained a terminal deoxynucleotidyl transferase-mediated deoxyuridine triphosphate biotin nick end-labelling (TUNEL) assay system. Stomach sections were permeabilized with proteinase $K$, and the 3'$\mathrm{OH}$ ends of the DNA fragments were then stained following the instructions supplied with the kit. The nuclei stained dark brown were considered to be apoptotic cells.

\section{RNA analysis}

Stomachs were trimmed and the total RNAs were extracted using TRIzol (Gibco BRL, Tokyo) according to the protocol supplied by the manufacturer. For Northern blot, the total RNA was electrophoresed on a 1.0\% agarose gel and was transferred to a nylon membrane (Amersham Pharmacia Biotech, Tokyo). Hybridization was performed with a probe of the human TGF $\alpha$ cDNA (917 bp) labeled with $\left[\alpha-{ }^{32} \mathrm{P}\right]$ deoxy-CTP. This probe recognizes human TGF $\alpha$ mRNA, but does not mouse TGF mRNA.

Mouse TGF $\alpha$ mRNA level was measured using a real time polymerase chain reaction (PCR) with glyceraldehyde-3phosphate dehydrogenase (GAPDH) as an internal control. The real time PCR was carried out using the ABI Prism 7700 Sequence Detector and soft (Applied Biosystems, Foster City, CA) using the DNA fluorescent dye SYBR Green detection. Primers were designed using the Primer Express design software (Applied Biosystems). The final result for each sample was normalized by the respective GAPDH value. Primer sequences are as follows: mouse TGFo: 5'-CCTGAGCACCCGAAGAT-3' and 5'-CCTTCCCTCATGCCTTACT-3'; GAPDH: 5'-GTCGTGGATCTGACGTGCC-3' and 5'-TGCCTGCTTCACCACCTTCT-3'.

\section{Western blot analysis}

Gastric tissue samples were trimmed and total protein from the gastric mucosa was homogenized in RIPA buffer containing a cocktail of protease inhibitors (phenylmethylsulphonyl fluoride, pepstatin, leupeptin, and aprotinin) (Roche Diagnostics, Mannheim, Germany). The supernatant was separated on an SDS-PAGE gel, and was then blotted to a polyvinylidene difluoride membrane. The membrane was probed with the following antibodies: antibodies to iNOS, COX-1, COX-2, HSP70, and Bcl-2, which were the same ones used for morphological studies; mouse monoclonal antibody to Bax (Santa Cruz Biotech.); rabbit polyclonal antibody to caspase 3 (Santa Cruz Biotech.); and mouse monoclonal antibody to actin filaments (Santa Cruz Biotech.). Antibody-reacted bands were detected utilizing an ECL detection system (Amersham, Buckinghamshire, UK).

\section{Measurement of gastrin}

Serum gastrin was measured using a gastrin radioimmunoassay kit (gastrin RIA kit, Dainabot, Tokyo, Japan). The antibody is specific for gastrin with an amide moiety at its carboxyl terminus.

\section{Measurement of Prostaglandin $\mathrm{E}_{2}$}

The gastric mucosa was homogenized at $4^{\circ} \mathrm{C}$ in lysis buffer. Homogenates were centrifuged at $12000 \mathrm{rpm}$ for $20 \mathrm{~min}$, and the supernatants were subjected to prostaglandin $\mathrm{E}_{2}$ assay using a Prostaglandin $\mathrm{E}_{2}$ Monoclonal Enzyme Immunoassay Kit (Cayman Chemical, Ann Arbor, MI), according to the manufacturer's instruction.

\section{Statistical analysis}

Statistical analysis was performed by repeated measure analysis of variance (ANOVA) for the total length of the gastric lesions by unpaired t-test for gastric mucosal blood flow decrease ratio. All values are expressed as the mean \pm SE. $\mathrm{P}<0.05$ was accepted as statistically significant.

\section{Results \\ Characterization of the TGF $\alpha$-expressing TG mouse gastric mucosa}

The WT CD1 strain and TGF $\alpha$-transgene expressing MT42 line mice grew similarly and showed no noticeable difference in their features, behaviors, or lifespans. The greatest thickness observed for the gastric wall and fundic glands were $3.50 \pm 0.18 \mathrm{~mm}$ and $2.33 \pm 0.20 \mathrm{~mm}$, respectively, in the WT mice, and $3.85 \pm 0.24 \mathrm{~mm}$ and $2.63 \pm 0.16 \mathrm{~mm}$, respectively, in the TG mice; there were no significant differences in the shape of the gastric mucosae and glands between the WT and TG mice. In addition to the normal appearance of the gastric mucosa, this TG mouse line also had a normal-appearing liver, pancreas, and other organs.

We then compared acid secretion capacity between the WT and TG mice. In the WT mice, maximal acid output increased significantly from basal level of $25 \pm 1.4 \mathrm{mEq} / \mathrm{h}$ to $50 \pm 5.8 \mathrm{mEq} / \mathrm{h}$ after the pentagastrin stimulation. By contrast, in the TG mice, maximal acid output increased to a less extent to $30 \pm 5.7 \mathrm{mEq} / \mathrm{h}$ from the basal output of $23 \pm 0.7 \mathrm{mEq} / \mathrm{h}(\mathrm{n}=5 \mathrm{in} \mathrm{WT}$ and TG mice $)$. The blunted acid output may reflect the reduced parietal cell mass in the TG mucosa (Figure 1e).

\section{Expression of TGF $\alpha$ transgene}

TGF $\alpha$-expressing cell-types were identified based on celltype-specific immunostaining and their mucosal location. TGF $\alpha$ was reportedly immunostained along the GSM cells in the gastric pit in humans [14] and rats [15], and along the mucous neck cell region in the FVB strain mice [16]. In the present study, brown-colored TGF $\alpha$-positive cells were distributed along the foveolar region of both the WT and TG mucosae, and along the lower glandular region of 
a

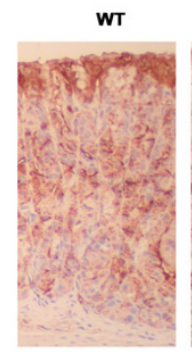

b

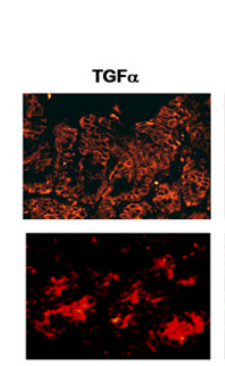

c

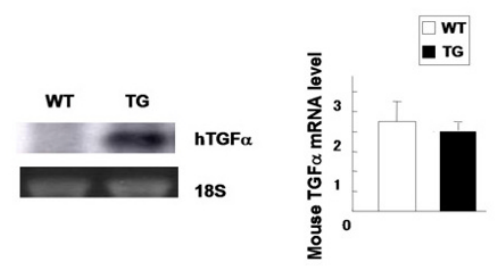

d

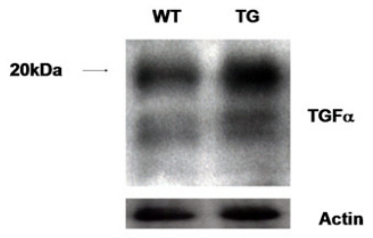

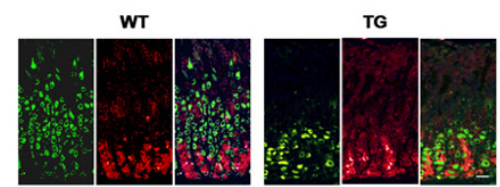

f

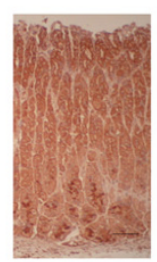

g

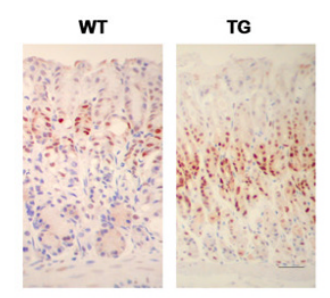

h

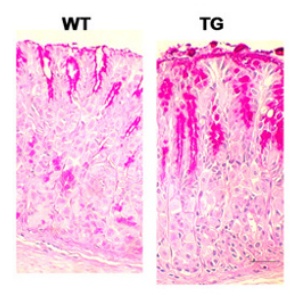

Figure I

Characterization of the TGF $\alpha$-expressing TG mucosa. Scale in each figure indicates $100 \mu \mathrm{m}$. (a) Distribution of TGF $\alpha$ expressing cells. Brown-colored TGF $\alpha$-positive cells were visible along the luminal pit region in the WT mucosa, the elongated foveolar pit region, and the lower one-third of the glandular region in the TG mucosa. (b) Overlap of red-colored TGF $\alpha$-positive cells and green-colored $\mathrm{H}^{+} / \mathrm{K}^{+}$-ATPase-positive parietal cells. Lower TGF $\alpha$-positive cells in cluster are distinct from the green-colored parietal cells in the TG mucosa. (c) Northern blot of human TGF $\alpha$ mRNA and PCR-amplified mouse TGF $\alpha$ mRNA. Human TGF $\alpha$ mRNA is expressed in the TG mucosa alone (left panel), but PCR-amplified mouse TGF $\alpha$ mRNA is expressed similarly in both WT and TG mucosae (right panel). (d) Western blot of TGF $\alpha$ intermediate forms. TGF $\alpha$ precursor $(20 \mathrm{kDa})$ and its intermediate forms are visualized more intensively in the TG mucosa than in the WT mucosa. (e) Localization of EGF receptor in the gastric mucosa. EGF receptor (EGF-R) was stained with Cy3 (red) and $\mathrm{H}^{+} / \mathrm{K}^{+}-\mathrm{ATPase}$ was stained with FITC (green). EGF-R was immunostained moderately in the upper pit region and strongly in the lower glandular region similarly in both the WT and TG mucosae. (f) Distribution of metallothionein in the gastric mucosa. Metallothionein is immunostained strongly in the lower glandular region, and moderately along the foveolar region. (g) Elongation of the gastric pit of the TG mucosa. PCNA-positive cells are distributed at the upper-third region in the WT gastric glands, whereas they are distributed more numerously and broadly in the middle glandular region. (h) PAS staining shows elongated pit in the TG mucosa. 
the TG mucosa (Figure 1a). The TGF $\alpha$-positive cells along the foveolar region appeared to be gastric pit cells, based by their location (Figure 1b, upper panel), and those along the lower glandular region of the TG mucosa did not overlap with the green-colored $\mathrm{H}^{+} / \mathrm{K}^{+}$-ATPase-positive parietal cells (Figure 1b, lower panel), but did overlap with the pepsinogen-positive chief cells (data not shown). The antibody we used for immunostaining for TGF $\alpha$ could not distinguish between human and mouse TGF $\alpha$, but its mRNA probe could do so for the Northern blot analysis. The human TGF $\alpha$-transgene was expressed in the TG mucosa while no expression was noted in the WT mucosa (Figure 1c, left panel). In contrast, endogenous mouse TGF $\alpha$ mRNA was similarly expressed in both the WT and TG mucosae by real time PCR (Figure 1c, right panel). TGF $\alpha$ is a 50 amino acid peptide, derived from its 160 amino acid membrane-spanning precursor cleaved by tumor necrosis factor- $\alpha$-converting enzyme (TACE) $[27,28]$. With the surplus expression of the human TGFotransgene in the TG mucosa, an approximately $20 \mathrm{kDa}$ TGF $\alpha$ precursor and its intermediate forms were increased by immunoblotting (Figure 1d).

Since both the precursor and processed forms were equally active for stimulating EGF-R [28], we further examined EGF-R localization in the mucosa. EGF-R was localized heavily in the lower chief cell cluster region and moderately in the mucous neck cell region and in the foveolar pit region in both the WT and TG mucosae (Figure 1e), as was reported previously for the rat gastric mucosa [15]. Since the TGF $\alpha$ transgene was controlled under the mouse metallothionein gene [20] and metallothionein has been reportedly produced in the gastric mucosa [29], we examined the metallothionein-expressing cell-types in the mucosa. Immunohistochemically, we noted metallothionein staining mostly along the lower glandular region and scatteringly along the pit region of the control CD1-strain gastric mucosa (Figure 1f). Thus, the distribution of TGF $\alpha$-expressing cell-types is similar to that of metallothionein-expressing cells in the TG gastric mucosa (Figures 1a and 1f).

In the WT mouse mucosa, the $\mathrm{H}^{+} / \mathrm{K}^{+}$-ATPase-positive parietal cells were spread widely over the glandular region except for the top-pit layer, whereas the $\mathrm{H}^{+} / \mathrm{K}^{+}$-ATPasepositive glandular region was reduced in height in the TG mucosa (Figure 1e). Indeed, the isthmus at the base of the pit region, which was confirmed by PCNA staining, was moved down to the middle of the TG mucosa (Figure 1g). Moreover, PCNA-positive cells were thickly distributed in the middle of the mucosa. Consistently, the PAS-stainingpositive foveolar pit was elongated in the TG mucosa in contrast to the short pit in the WT mucosa (Figure 1h). Thus, although the height of the gastric mucosa was similar between the WT and TG mucosae, the proliferative zone was moved down and the foveolar pit region was more elongated with a reduced glandular region in the TG mocosa. Since the growth of pit cells is strongly enhanced by gastrin $[25,30]$, we compared the serum gastrin levels between the WT and TG mice but found no increase in the levels of serum gastrin in the TG mouse (WT, $213 \pm 41 \mathrm{pg} /$ $\mathrm{ml} ; \mathrm{TG}, 263 \pm 47 \mathrm{pg} / \mathrm{ml}, \mathrm{n}=5, \mathrm{p}=0.438)$.

\section{Ethanol-induced gastric injury in the WT and TG mouse mucosae}

Orogastric administration of acidified ethanol $(100 \mu \mathrm{l})$ caused hemorrhagic injury in the TG mucosa (Figure 2a, left). Histologically the injury peeled off the pit and isthmus regions and reached to the mid-glandular region (Figure 2b, left). In contrast, this sort of injury in the TG mouse mucosa was not notable (Figure $2 \mathrm{a}$, right). The injury was histologically limited to the luminal pit region (Figure 2b, right). In the WT mucosa, the injured area increased rapidly with a peak at $6 \mathrm{~h}$ after the ethanol administration, whereas in the TG mucosa the area increased slowly and minimally without a marked peak (Figure 2c). Consistently, apoptotic cells shown by the TUNEL staining distributed deeply to the lower glandular region $3 \mathrm{~h}$ after the ethanol administration in the WT mucosa, whereas the apoptotic cells were confined to the pit region but did not extend to the glandular region in the TG mucosa (Figure 2d).

\section{Gastric mucosal blood flow in the ethanol-treated mucosa} Although a number of cytoprotective regulatory factors have been reported, including NO, CGRP, COX2, and HSP70 $[12,13,31,32]$, mucosal blood flow has been proposed as a primary factor for the protection and restitution of ethanol-induced gastric injury [1,33]. We measured gastric blood flow by placing a probe of the laser Doppler flowmeter on the gastric mucosa accessed via an exposed abdominal wall in the anesthetized mouse. Gastric blood flow decreased marked by $43.5 \pm$ $6.37 \%$ after the ethanol administration on the gastric mucosa of the WT mouse (Figure 3). In contrast, it only decreased by $17.2 \pm 9.21 \%$ after the ethanol administration on the TG mucosa (Figure 3). Thus, the gastric blood flow was well maintained in the TG mucosa even after ethanol treatment. Since mucosal ischemia is one of the most important ulcerogenic factors [33], the maintenance of gastric blood flow does appear to be an essential factor for mucosal protection.

\section{Expression of cytoprotective proteins: NO synthase, COX- 2, and HSP70}

To explore the mechanism of high blood flow maintenance in the TG mucosa, we examined the expression of NO synthases, which makes NO from arginine, and relaxes vascular smooth muscles via cGMP-dependent protein kinase [34]. There are three types of NO synthase 
a

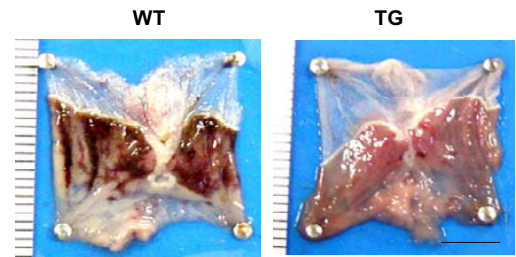

b

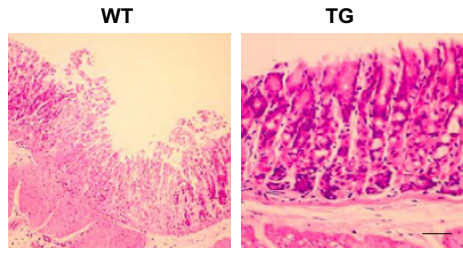

C

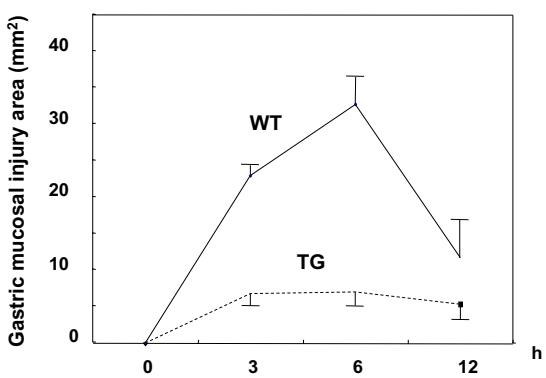

d

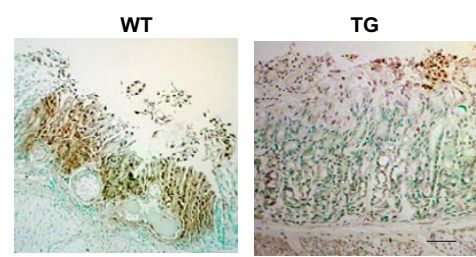

\section{Figure 2}

Ethanol-induced gastric injury in the gastric mucosae. (a) Macroscopic view of the gastric mucosa. Scale: 5 mm. Both mucosae are $6 \mathrm{~h}$ after ethanol administration. Note that the WT mucosa displays extensive hemorrhagic lesions, in contrast, the TG mucosa looks undamaged after ethanol administration. (b) Hematoxylin and eosin staining of ethanol-injured WT mucosa (left) and TG mucosa (right). Note the deep ulcer formation in the WT mucosa. Scale: I00 $\mu \mathrm{m}$. (c) Time course of ethanol-induced gastric injury. Injured area is plotted against time up to $12 \mathrm{~h}$ after the ethanol administration. Each point represents an average of five mice. $p<0.05$ (d) TUNEL staining of WT mucosa (left) and TG mucosa (right). Both sections are consecutive to those in $2 B$, respectively. Apoptotic cells are visible with dark-brown nuclei. Numerous apoptotic cells are noted in the WT mucosa. All photos were $6 \mathrm{~h}$ after the ethanol administration. Scale: $100 \mu \mathrm{m}$. 


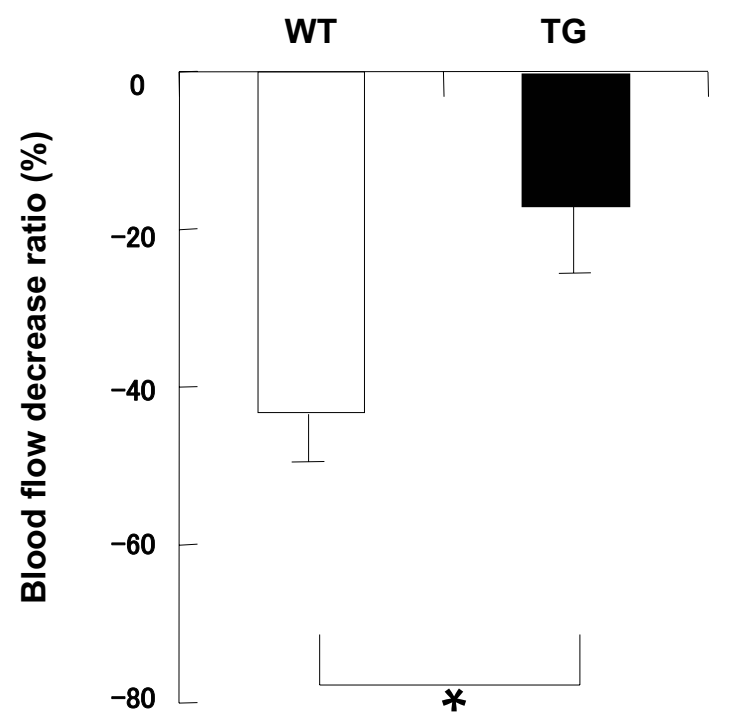

Figure 3

Assessment of gastric mucosal blood flow in the gastric mucosae. Gastric mucosal blood flow was assessed by comparing the blood flow ratio before and after the ethanol treatment. The ratio was obtained as a percent against the blood flow before the treatment, which was much larger in the WT mucosa than in the TG mucosa. ${ }^{*} p<0.03$.

(NOS): neural NOS (nNOS), inducible NOS (iNOS), and endothelial NOS (eNOS). nNOS and eNOS are constitutively expressed, whereas iNOS is induced upon gastric injury [35]. nNOS was distributed similarly to the PASstaining over the foveolar pit region (Figure 1g); it was observed over the elongated pit of the TG mucosa and was limited to the luminal pit of the WT mucosa (Figure 4a). eNOS was weakly scattered over the entire gastric mucosa similarly in both the WT and TG mucosae (data not shown). The iNOS staining was negligible in the WT mucosa, although it was highly induced in the lower glandular region after the mucosa was exposed to ethanol (Figure $4 \mathrm{~b}$ ). In the TG mucosa, iNOS was constitutively expressed in the lower glandular region similarly before and after the injury (Figure 4b), which appears to further contribute to the maintenance of high blood flow.

Prostaglandins were proposed as a major cytoprotective factor over three decades ago [8] and their roles have been extensively studied $[36,37]$. The role of the prostaglandinforming enzymes, COX-1 and COX-2, has been controversial in the mucosal protection against gastric irritants $[7,11,32]$. We examined the expression of COX in the WT and TG mucosae during ethanol injury. The expression of COX-1 did not differ between the WT and TG mucosae,

\section{A}

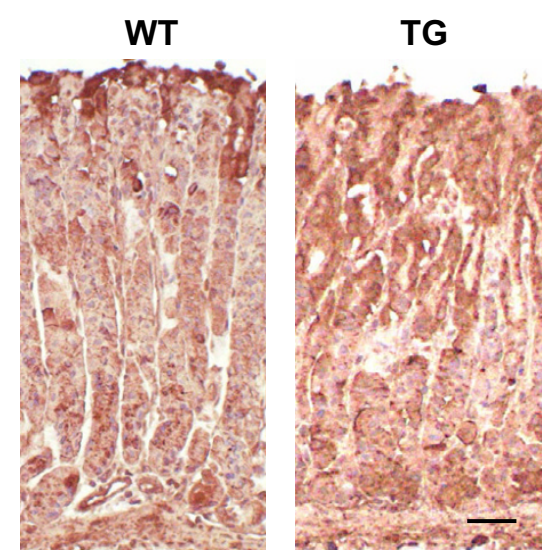

B
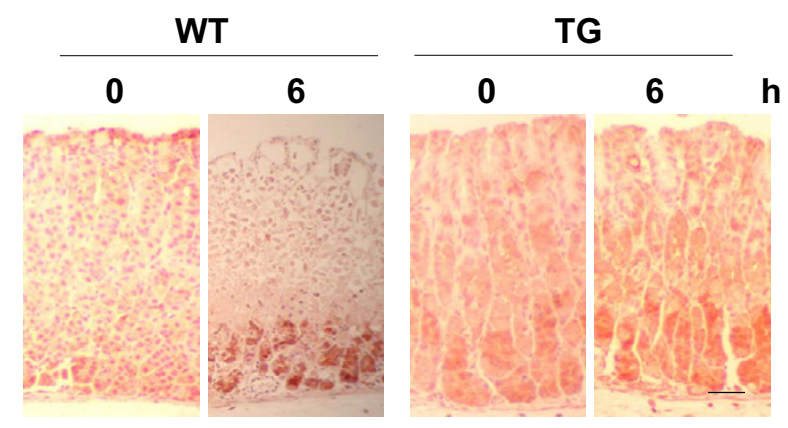

\section{Figure 4}

Immunostaining of NO synthases in the gastric mucosa. Scale: $100 \mu \mathrm{m}$. (a) nNOS immunostaining. nNOS was visible along the pit region, resulting in its wider distribution along the elongated pit in the TG mucosa. (b) iNOS immunostaining. iNOS was induced in the lower glandular region after ethanol injury in the WT mucosa, whereas it was constitutively expressed in the same region of the TG mucosa irrespective of ethanol injury.

nor before or after the ethanol injury (Figure 5b). COX-2 was not detectable in the WT mucosa, but its expression became evident $6 \mathrm{~h}$ after ethanol injury, and its staining was localized to the lower glandular region (Figure $5 \mathrm{a}$ and $5 b)$. In the TG mucosa, the COX-2 immunostaining was intense at the same region even before the injury and remained positive after the injury (Figure 5a). Since COXs have been shown to be expressed in mesenchymal cells such as fibroblasts and mononuclear cells in the gastric mucosa [38], and the streptoavidin/biotin/HPR method sometimes presents false-positive staining, we performed immunofluorescent staining using a frozen section which 
A

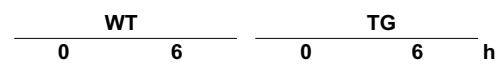

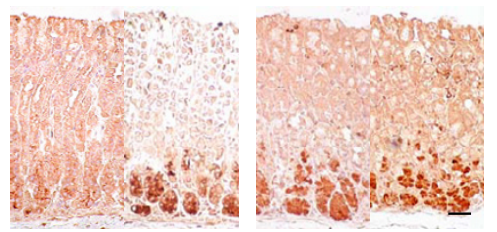

B

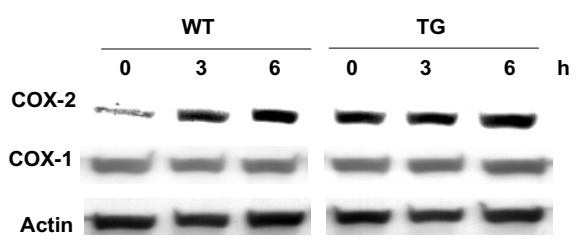

C

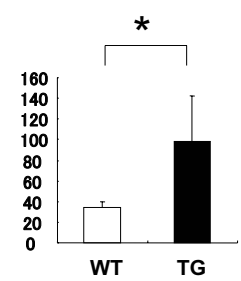

D

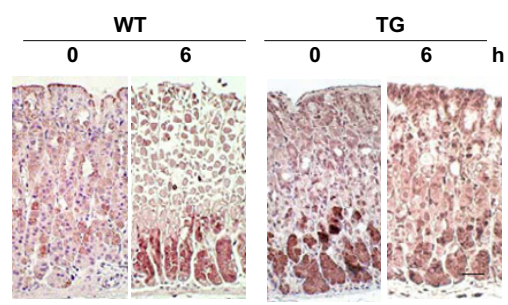

\section{Figure 5}

COX-2 and NFKB expression in the gastric mucosa. (a) Immunostaining of COX-2. COX-2 was intensively induced after the injury at the lower glandular region of the WT mucosa, whereas it was constitutively expressed in the same region of the TG mucosa even before the injury. Ethanol-injured mucosa was stained $6 \mathrm{~h}$ after the ethanol administration. Scale: $100 \mu \mathrm{m}$. (b) Immunoblotting of COX-2 and COX-I. The blots were measured 0, 3, and $6 \mathrm{~h}$ after the injury. Actin filaments were used as a control. Note that COX-2 was intensively expressed before the injury in the TG mucosa. (c) Measurement of prostaglan$\operatorname{din} E_{2}$. Prostaglandin $E_{2}$ levels were measured before the ethanol treatment in the WT and TG mucosae. $n=5, p=0.013$. (d) Immunostaining of NFKB. NFKB was intensively induced after the injury at the same lower glandular region of the WT mucosa as was COX-2. In contrast, NFKB was constitutively expressed in the same region of the TG mucosa even before the injury. Scale: $100 \mu \mathrm{m}$. 
confirmed COX expression similarly in the lower glandular region of the TG mucosa (data not shown). By immunoblotting, COX-2 increased after the injury in the WT mucosa, whereas it was highly elevated to a similar extent before and after the injury (Figure 5b). Consistently, prostaglandin $\mathrm{E}_{2}$ levels were significantly higher in the TG mucosa than in the WT mucosa (Figure 5c). Furthermore, $\mathrm{NFKB}$, a transcription factor responsible for COX-2 gene expression, was localized to the lower glandular region of the TG mucosa even before the ethanol treatment (Figure $5 \mathrm{~d})$, suggesting that TGF $\alpha$ transgene causes the constitutive expression of NFKB [21].

Gastric irritants are known to induce heat shock protein 70 (HSP70), which chaperones denatured proteins for renaturation or clearance [39]. HSP70 was not detected in the WT mucosa, but after ethanol injury it was observed extensively over the glandular region, and scatteringly in the pit region of the WT mucosa (Figure 6a). In contrast, it was visible at the lower glandular region of the TG mucosa similarly before and after ethanol treatment (Figure 6a). By immunoblotting, HSP70 was not detected before ethanol injury but appeared $3 \mathrm{~h}$ to $12 \mathrm{~h}$ after the injury in the WT mucosa (Figure 6b). In contrast, it was already elevated before the injury and increased moderately after the injury (Figure 6b).

Collectively, the three cytoprotection-associated proteins, iNOS, COX-2, and HSP70, were negligible in expression before the injury and highly induced after the injury in the WT mucosa, but they stayed elevated similarly before and after the injury in the TG mucosa.

\section{Expression of apoptosis-associated proteins in the gastric mucosa}

As shown with the TUNEL staining in Figure $2 \mathrm{~d}$, the TGFo-expressing mucosa was strongly resistant to ethanol injury. Initially, we examined the expression of anti-apoptotic Bcl-2 and pro-apoptotic Bax by immunoblotting. Bcl-2 and Bax were slightly expressed in the WT mucosa before the injury; after the injury, Bax increased intensively whereas $\mathrm{Bcl}-2$ increased to a lesser extent (Figure $7 \mathrm{a})$. In the TG mucosa, Bcl-2 was expressed even before the injury and remained elevated after the injury, whereas Bax decreased to a negligible level after the injury. By immunostaining, $\mathrm{Bcl}-2$ was positive in the lower glandular region of the TG mucosa before the injury, but no staining was visible in the WT mucosa. After the ethanol injury, Bcl-2 appeared strongly along the periphery of the injured lesion in the WT mucosa, in contrast, it stained similarly to the pretreatment level in the TG mucosa (Figure $7 \mathrm{~b}$ ). Thus, the constitutive expression of $\mathrm{Bcl}-2$ may contribute to the anti-apoptotic feature of the TG mucosa against ethanol injury. Evidence of the active form of caspase-3, an executive caspase, was consistently absent in

\section{a}

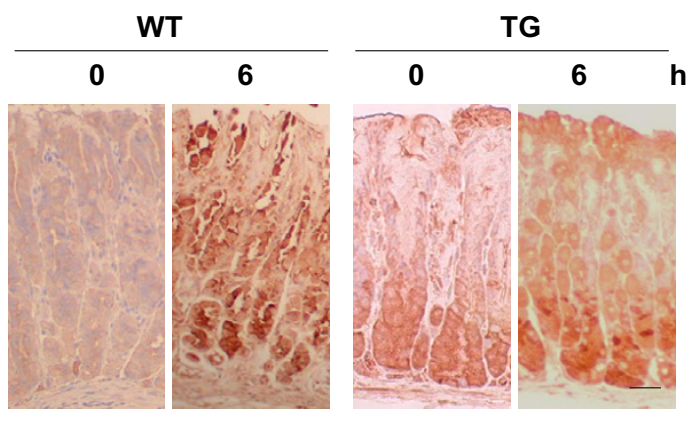

b

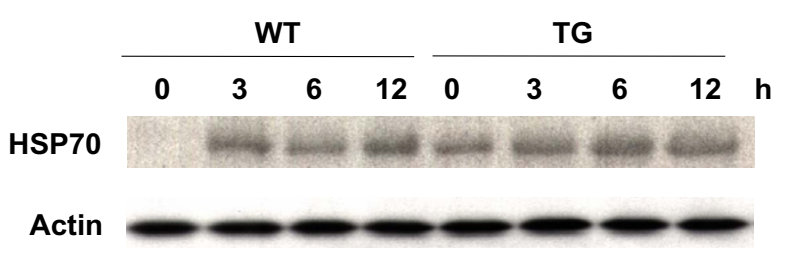

Figure 6

HSP70 expression in the gastric mucosa. (a) Immunostaining of HSP70. HSP70 was induced along the necrotic region and the lower glandular region of the WT mucosa after ethanol injury, whereas it was constitutively expressed in the lower glandular region of the TG mucosa before and after the injury. Ethanol-injured mucosa was stained $6 \mathrm{~h}$ after the ethanol administration. Scale: $100 \mu \mathrm{m}$. (b) Immunoblotting of HSP70. HSP70 blot was assessed 0, 3, 6, $12 \mathrm{~h}$ after the ethanol injury. HSP was induced after ethanol injury in the WT mucosa, while it was constitutively expressed in the TG mucosa before and after the injury.

the TG mucosal cell extract before and after the injury, whereas it was intensively detected in the WT mucosa after the injury, although the proform remained similarly before and after the injury in both the WT and TG mucosae (Figure 7c).

\section{Discussion}

EGF family growth factors including TGFa have been proposed as integrative cytoprotective factors against gastric injury $[2,4]$. The effects of TGFa have been tested by administrating it to animals or culture cells for a short term, and thus the reported cytoprotective mechanisms of TGFa have been somewhat variable $[7,12,24,31,40-42]$. TGFa is known to be a potent growth-promoting factor leading to hypertrophic growth in the gastric mucosae $[19,20]$. In contrast, the EGF-R signal is known to activate 
a

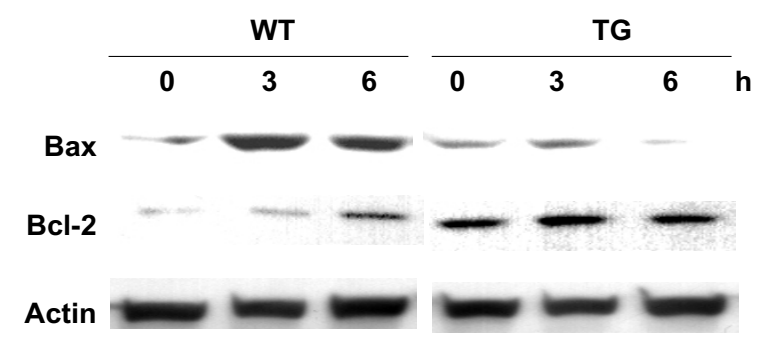

b

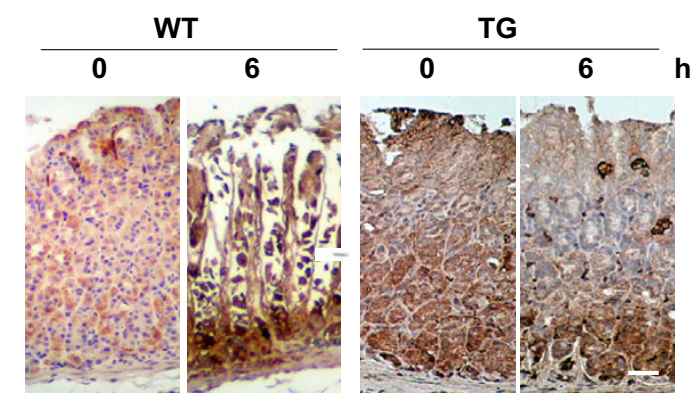

C

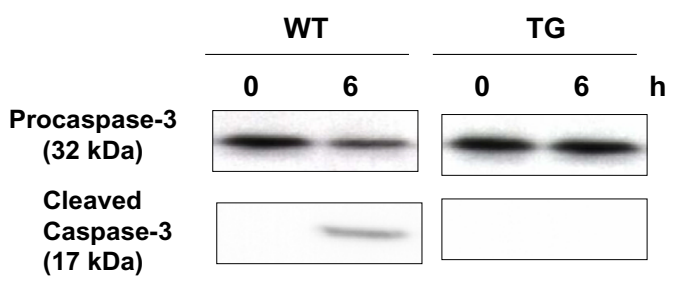

\section{Figure 7}

Expression of apoptosis-associated proteins. (a) Immunoblot of Bax and Bcl-2. Bax was strongly induced at the $3 \mathrm{~h}$ and $6 \mathrm{~h}$ time points in the WT mucosa, whereas it was reduced to a negligible level in the TG mucosa after ethanol injury. Bcl-2 was stably expressed similarly before and after the injury in the TG mucosa, whereas it was increased to some extent at $6 \mathrm{~h}$ after the injury in the WT mucosa. (b) Immunostaining of Bcl-2. Bcl-2 was not visible in the TG mucosa before the injury, but appeared along the border region of necrotic area after the injury. In contrast, $\mathrm{Bcl}-2$ was constitutively induced over the TG mucosa even before the injury, and the staining was confined to the lower glandular region after the injury. Scale: $100 \mu \mathrm{m}$. (c) Immunoblot of caspase 3. After the injury, a $17 \mathrm{kDa}$ active form of caspase 3 appeared in the WT mucosa, whereas it did not in the TG mucosa. A $32 \mathrm{kDa}$ proform was unchanged both in the WT and TG mucosae.

non-proliferative functions such as the induction of potent cytoprotective trefoil peptides, which are produced from the gastrointestinal mucosa, through an EGF-R/MAP kinase pathway [43]. Therefore, although high levels of TGFa can cause hypertrophic gastropathy, appropriate levels appear to maintain mucosal resistance to gastric injury. However, since the broad presence of PCNA-positive cells shown in Figure 1g indicates the proliferative action of TGFa to gastric precursor cells in the TG mucosa, it does not seem appropriate to categorize the action of TGFa as either proliferative or non-proliferative for gastric protection. More appropriate is to evaluate the diverse effects of TGFa using a long-term TGFa-expressing model. Using such a TGFa-transgene-expressing TG mouse model whose gastric mucosa showed a strong resistance to ethanol injury (Figure 2), we found that the integrative mechanisms of TGFa involve at least three categories of cytoprotective regulators: NO synthases in relation with gastric blood flow, COX-2, and apoptosis-associated regulators such as Bcl-2 and Bax.

Gastric blood flow is known to contribute substantially to mucosal protection against gastric injury [33]. In the present study, a laser Doppler flowmeter analysis revealed a significant maintenance of blood flow when acidified ethanol was applied onto the mucosal surface of the TG mouse (Figure 3). Since vascular dilation occurs even in the high dose capsaicin-denervated gastric mucosa where increased levels of NO contribute greatly [13], we confirmed the expression of NOS in the mucosa. nNOS was expressed at the luminal pit region as previously reported [35]. Since the pit region is elongated to half of the gastric gland in length in the TG mucosa, the nNOS-expressing region was much wider than that in the WT mucosa. Furthermore, iNOS was constitutively expressed along the lower glandular region in the TG mucosa, in contrast to the negligible expression of iNOS unless ethanol was applied to the WT mucosa (Figure 4). nNOS has been reported to be induced by EGF in guinea pig gastric mucosal primary-cultured cells [44], and in human HaCaT keratinocytes [45]. In contrast, iNOS, a key regulator of oxidant-induced epithelial barrier disruption, has been reportedly downregulated through an EGF-R downstream $\zeta$-isoform of protein kinase $\mathrm{C}$ for gastric protection using colorectal carcinoma-derived Caco- 2 cells [46]. We postulate that the long-term effect of TGF $\alpha$ on iNOS induction may be different from its short-term effect seen in culture cells.

Previously, prostaglandins have been shown to increase in parallel with the expression of COX-2 protein after ulcer formation in rats [32]. However, intraperitoneal administration of TGF $\alpha$ did not induce prostaglandin $\mathrm{E}_{2}$ release into the gastric juice nor did it increase gastric tissue levels of prostaglandin $E_{2}$ [7]. The protective effect of TGFo to ethanol-induced mucosal injury was not interrupted by indomethacin-induced depletion of prostaglandin $E_{2}$ in 
the rat gastric mucosa [42]. Although the roles of prostaglandins in gastric protection are controvertial, we found that COX-2 and its upstream transcription factor NFKB are markedly expressed in the TGF $\alpha$-expressing TG mucosa (Figure $5 \mathrm{a}$ and $5 \mathrm{~d}$ ). Our findings suggest that COX-2 is induced by NFKB under the control of TGF $\alpha$ in gastric mucosal cells. Consistently, prostaglandin $\mathrm{E}_{2}$ levels were muchi more elevated in the TG mucosa than in the WT mucosa (Figure 5c).

In response to environmental or physiological stress, such as exposure to heat, ethanol, heavy metals, and waterimmersion stress, heat shock proteins such as HSP70 are induced in the gastric mucosa $[39,47]$. HSPs are known to play a role in refolding of denatured proteins and facilitate the recovery of damaged cellular functions. HSP70 is also thought to interrupt stress-induced apoptosis pathways at several steps, including a cytochrome $\mathrm{C}$ releasing step from mitochondria, and a pro-caspase activation step by directly interacting with Apaf-1 [48]. In the present study, HSP70 was already elevated in the TG mucosa before ethanol injury, in contrast to the almost completely lack of HSP70 expression without injury in the WT mucosa (Figure 6). Together with HSP70, anti-apoptotic Bcl-2 remained similarly elevated before and after the ethanol injury, but pro-apoptotic Bax was down-regulated in the TG mucosa after the injury (Figure 7). Bcl-2 is an antiapoptotic protein which resides on the mitochondrial outer membrane and inhibits channel formation of Bax, a pro-apoptotic protein of the same Bcl-2 family, through which cytochrome $C$ leaks to the cytoplasm $[49,50]$. Thus, constitutive expression of $\mathrm{Bcl}-2$ by TGF $\alpha$ may overcome unfavorable ethanol-exposure stress at least by suppressing Bax activation. Once the Bcl-2 function is suppressed, cytochrome $\mathrm{C}$ and other apoptogenic factors are released through the Bax channel, and cytochrome $\mathrm{C}$ associates with Apaf- 1 to promote the activation of the initiator caspase, pro-caspase 9, whose active form subsequently activates the effecter caspase, pro-caspase 3. Caspase 3 cleaves the inhibitor of caspase-activated DNase (ICAD) to release CAD, which then causes DNA fragmentation $[50,51]$. In the present study, active $17 \mathrm{kDa}$ caspase 3 was not formed in the TG mucosa, whereas it was markedly formed in the WT mucosa after the injury. Thus, we propose that the inhibitory effect of $\mathrm{Bcl}-2$ on the release of cytochrome C, and the HSP70 block of cytochrome C-initiated apoptosome formation to produce activated caspase 9, resulted in the suppression of caspase 3 formation from its precursor [50,52].

The strong resistance of TGFo-expressing gastric mucosa to ethanol injury appears to involve at least three cytoprotective mechanisms: a well-maintained gastric blood flow partly due to NO synthase expression by TGF $\alpha$; constitutive expression of COX-2, which produces prostaglandins that may recruit GSM precursor cells to the injured pit region [53]; and upregulation of anti-apoptotic proteins such as HSP70 and Bcl-2, downregulation of pro-apoptotic Bax, and inhibition of pro-caspase 3 activation. These distinct cytoprotection mechanisms appear to connect in an integrated manner.

\section{Conclusion}

We propose that non-pathological levels of long-term TGF $\alpha$ expression may enhance the protective capacity of the gastric mucosa against injury and may help maintain the integration of mucosal functions by activating other essential cytoprotective factors such as mucosal blood flow, COX-2, and anti-apoptotic regulators such as HSP70 and $\mathrm{Bcl}-2$ through these interconnecting pathways.

\section{Abbreviations}

TGF $\alpha$, transforming growth factor $\alpha$; TG, transgenic; WT, wild-type; EGF-R, epidermal growth factor receptor; COX, cyclooxygenase: NOS, nitric oxide synthase; HSP, heat shock protein; GSM, gastric surface mucosa; HRP, horseradish peroxydase

\section{Competing interests}

The author(s) declare that they have no competing interests.

\section{Authors' contributions}

TK performed immunohistochemistry, Western blotting, Northern blotting, maintained transgenic mice, and performed genotype analysis with some help from SK, NS, $\mathrm{NH}$ and KS. MY performed gastric blood flow measurements. HT, TT and MM supervised the first author TK. All authors read and approved the final manuscript.

\section{Acknowledgements}

We thank Ms. M. Kosaki for secretarial assistance. This work was supported by a grant of the 2 Ist Century Center of Exellence Program, and that from the Ministry of Education, Culture, Sports, Science and Technology of Japan.

\section{References}

I. Gonul B, Akbulut KG, Ozer C, Yetkin G, Celebi N: The role of transforming growth factor alpha formulation on aspirininduced ulcer healing and oxidant stress in the gastric mucosa. Surg Today 2004, 34:1035-1040.

2. Barnard JA, Beauchamp RD, Russell WE, Dubois RN, Coffey RJ: Epidermal growth factor-related peptides and their relevance to gastrointestinal pathophysiology. Gastroenterology 1995, 1 08:564-580.

3. Kamimura H, Konda $\mathrm{Y}$, Yokota H, Takenoshita S, Nagamachi $\mathrm{Y}$, Kuwano $H$, Takeuchi $T$ : Kex2 family endoprotease furin is expressed specifically in pit-region parietal cells of the rat gastric mucosa. Am J Physiol 1999, 277:G I83-GI90.

4. Nakajima T, Konda Y, Izumi Y, Kanai M, Hayashi N, Chiba T, Takeuchi $\mathrm{T}$ : Gastrin stimulates the growth of gastric pit cell precursors by inducing its own receptors. Am J Physiol Gastrointest Liver Physiol 2002, 282:G359-G366.

5. Potter $\mathrm{CL}$, Hanson PJ: Exogenous nitric oxide inhibits apoptosis in guinea pig gastric mucous cells. Gut 2000, 46:156-162. 
6. Robert A, Nezamis JE, Lancaster C, Hanchar AJ: Cytoprotection by prostaglandins in rats. Prevention of gastric necrosis produced by alcohol, $\mathrm{HCl}, \mathrm{NaOH}$, hypertonic $\mathrm{NaCl}$, and thermal injury. Gastroenterology 1979, 77:433-43.

7. Slice LW, Hodikian R, Zhukova E: Gastrin and EGF synergistically induce cyclooxygenase-2 expression in Swiss 3T3 fibroblasts that express the CCK2 receptor. J Cell Physiol 2003, 196:454-463.

8. Romano M, Polk WH, Awad JA, Arteaga CL, Nanney LB, Wargovich $\mathrm{MJ}$, Kraus ER, Boland CR, Coffey RJ: Transforming growth factor alpha protection against drug-induced injury to the rat gastric mucosa in vivo. I Clin Invest 1992, 90:2409-242 I.

9. Sugiyama N, Tabuchi Y, Horiuchi T, Obinata M, Furusawa M: Establishment of gastric surface mucous cell lines from transgenic mice harboring temperature-sensitive simian virus $\mathbf{4 0}$ large T-antigen gene. Exp Cell Res 1993, 209:382-387.

10. Sunnarborg SW, Hinkle CL, Stevenson M, Russell WE, Raska CS, Peschon JJ, Castner BJ, Gerhart MJ, Paxton RJ, Black RA, Lee DC: Tumor necrosis factor-alpha converting enzyme (TACE) regulates epidermal growth factor receptor ligand availability. J Biol Chem 2002, 277: I 2838- 2845.

II. Konda $Y$, Yokota H, Kayo T, Horiuchi T, Sugiyama N, Tanaka S, Takata K, Takeuchi T: Proprotein-processing endoprotease furin controls the growth and differentiation of gastric surface mucous cells. J Clin Invest 1997, 99:1842-185I.

12. Karam S, Leblond CP: Origin and migratory pathways of the eleven epithelial cell types present in the body of the mouse stomach. Microsc Res Tech 1995, 3 1:193-214.

13. Massague J: Transforming growth factor-alpha. A model for membrane-anchored growth factors. I Biol Chem 1990, 265:21393-21396.

14. Orsini B, Calabro A, Milani S, Grappone C, Herbst H, Surrenti C: Localization of epidermal growth factor/transforming growth factor-alpha receptor in the human gastric mucosa. An immunohistochemical and in situ hybridization study. Virchows Arch A Pathol Anat Histopathol 1993, 423:57-63.

15. Kang JY, Teng CH, Chen FC, Wee A: Role of capsaicin sensitive nerves in epidermal growth factor effects on gastric mucosal injury and blood flow. Gut 1998, 42:344-350.

16. Takano H, Satoh M, Shimada A, Sagai M, Yoshikawa T, Tohyama C Cytoprotection by metallothionein against gastroduodenal mucosal injury caused by ethanol in mice. Lab lnvest 2000 , 80:37I-377.

17. Peskar BM: Neural aspects of prostaglandin involvement in gastric mucosal defense. J Physiol Pharmacol 200I, 52:555-568.

18. Chen MC, Lee AT, Soll AH: Mitogenic response of canine fundic epithelial cells in short-term culture to transforming growth factor alpha and insulinlike growth factor I. J Clin Invest |99|, 87:1716-1723.

19. Dempsey PJ, Goldenring JR, Soroka CJ, Modlin IM, McClure RW, Lind CD, Ahlquist DA, Pittelkow MR, Lee DC, Sandgren EP: Possible role of transforming growth factor alpha in the pathogenesis of Menetrier's disease: supportive evidence form humans and transgenic mice. Gastroenterology 1992, 103:1950-1963.

20. Takahashi S, Shigeta J, Inoue H, Tanabe T, Okabe S: Localization of cyclooxygenase-2 and regulation of its MRNA expression in gastric ulcers in rats. Am J Physiol Gastrointest Liver Physiol 1998, 275:GI|37-GII45.

21. Karam SM, Leblond CP: Dynamics of epithelial cells in the corpus of the mouse stomach. I. Identification of proliferative cell types and pinpointing of the stem cell. Anat Rec 1993, 236:259-279.

22. Chen MC, Solomon TE, Kui R, Soll AH: Apical EGF receptors regulate epithelial barrier to gastric acid: endogenous TGFalpha is an essential facilitator. Am J Physiol Gastrointest Liver Physiol 2002, 283:GI 098-GI I06.

23. Li Z, Jansen M, Ogburn K, Salvatierra L, Hunter L, Mathew S, Figueiredo-Pereira ME: Neurotoxic prostaglandin J2 enhances cyclooxygenase- 2 expression in neuronal cells through the p38MAPK pathway: a death wish? I Neurosci Res 2004, 78:824-836.

24. Zhang B, Hosaka M, Sawada Y, Torii S, Mizutani S, Ogata M, Izumi T, Takeuchi T: Parathyroid hormone-related protein induces insulin expression through activation of MAP kinase-specific phosphatase-I that dephosphorylates c-Jun NH2-terminal kinase in pancreatic beta-cells. Diabetes 2003, 52:2720-2730.
25. Konturek PC, Brzozowski T, Kania J, Konturek SJ, Hahn EG: Nitric oxide-releasing aspirin protects gastric mucosa against ethanol damage in rats with functional ablation of sensory nerves. Inflamm Res 2003, 52:359-365.

26. Takagi H, Jhappan C, Sharp R, Merlino G: Hypertrophic gastropathy resembling Menetrier's disease in transgenic mice overexpressing transforming growth factor alpha in the stomach. J Clin Invest 1992, 90:1161-1 I67.

27. Milani S, Calabro A: Role of growth factors and their receptors in gastric ulcer healing. Microsc Res Tech 200I, 53:360-37I.

28. Takagi H, Fukusato T, Kawaharada U, Kuboyama S, Merlino G, Tsutsumi $Y$ : Histochemical analysis of hyperplastic stomach of TGF-alpha transgenic mice. Dig Dis Sci 1997, 42:91-98.

29. Taupin D, Wu DC, Jeon WK, Devaney K, Wang TC, Podolsky DK: The trefoil gene family are coordinately expressed immediate-early genes: EGF receptor- and MAP kinase-dependent interregulation. J Clin Invest 1999, 103:R3 I-R38.

30. Oshima M, Dinchuk JE, Kargman SL, Oshima H, Hancock B, Kwong E, Trzaskos JM, Evans JF, Taketo MM: Suppression of intestinal polyposis in Apc delta7 16 knockout mice by inhibition of cyclooxygenase 2 (COX-2). Cell 1996, 87:803-809.

31. Mizuno H, Sakamoto C, Matsuda K, Wada K, Uchida T, Noguchi H, Akamatsu T, Kasuga M: Induction of cyclooxygenase 2 in gastric mucosal lesions and its inhibition by the specific antagonist delays healing in mice. Gastroenterology 1997, I I 2:387-397.

32. Nasim MM, Thomas DM, Alison MR, Filipe MI: Transforming growth factor alpha expression in normal gastric mucosa, intestinal metaplasia, dysplasia and gastric carcinoma - an immunohistochemical study. Histopathology 1992, 20:339-343.

33. Vongthavaravat V, Mesiya S, Saymeh L, Xia Y, Harty RF: Mechanisms of transforming growth factor-alpha (TGF-alpha) induced gastroprotection against ethanol in the rat: roles of sensory neurons, sensory neuropeptides, and prostaglandins. Dig Dis Sci 2003, 48:329-333.

34. Rokutan K, Teshima S, Kawai T, Kawahara T, Kusumoro K, Mizushima T, Kishi K: Geranylgeranylacetone stimulates mucin synthesis in cultured guinea pig gastric pit cells by inducing a neuronal nitric oxide synthase. J Gastroenterol 2000, 35:673-68I.

35. Hirose M, Miwa H, Kobayashi O, Oshida K, Misawa H, Kurosawa A, Watanabe S, Sato N: Inhibition of proliferation of gastric epithelial cells by a cyclooxygenase 2 inhibitor, JTE522, is also mediated by a PGE2-independent pathway. Aliment Pharmacol Ther 16 Suppl 2002, 2:83-89.

36. Helmer KS, West SD, Shipley GL, Chang L, Cui Y, Mailman D, Mercer DW: Gastric nitric oxide synthase expression during endotoxemia: implications in mucosal defense in rats. Gastroenterology 2002, I 23:173-186.

37. Yanaka A, Suzuki H, Shibahara T, Matsui H, Nakahara A, Tanaka N: EGF promotes gastric mucosal restitution by activating $\mathrm{Na}(+) / \mathbf{H}(+)$ exchange of epithelial cells. Am J Physiol Gastrointest Liver Physiol 2002, 282:G866-G876.

38. Polk WH Jr, Dempsey PJ, Russell WE, Brown PI, Beauchamp RD, Barnard JA, Coffey RJ Jr: Increased production of transforming growth factor alpha following acute gastric injury. Gastroenterology 1992, 102: 1467-1474

39. Wallace JL: Nonsteroidal anti-inflammatory drugs and the gastrointestinal tract. Mechanisms of protection and healing: current knowledge and future research. Am J Med 200I, II $0: 195-23 S$

40. Halter F, Tarnawski AS, Schmassmann A, Peskar BM: Cyclooxygenase 2-implications on maintenance of gastric mucosal integ. rity and ulcer healing: controversial issues and perspectives. Gut 200I, 49:443-453.

4I. Kanai M, Konda Y, Nakajima T, Izumi Y, Takeuchi T, Chiba T: TGFalpha inhibits apoptosis of murine gastric pit cells through an NF-kappaB-dependent pathway. Gastroenterology 2001, | 21:56-67.

42. Watanabe D, Otaka M, Mikami K-I, Yoneyama K, Goto T, Miura K, Ohshima S, Lin J-G, Shibuya T, Segawa D, Kataoka E, Konishi N, Odashima M, Sugawara M, Watanabe S: Expression of a 72-kDa heat shock protein, and its cytoprotective function, in gastric mucosa in cirrhotic rats. I Gastroenterol 2004, 39:724-733.

43. Tsukimi $Y$, Okabe $S$ : Recent advances in gastrointestinal pathophysiology: role of heat shock proteins in mucosal defense and ulcer healing. Biol Pharm Bull 200I, 24:I-9. 
44. Sasaki E, Tominaga $\mathrm{K}$, Watanabe $\mathrm{T}$, Fujiwara $\mathrm{Y}$, Oshitani $\mathrm{N}$, Matsumoto T, Higuchi K, Tarnawski AS, Arakawa T: COX-2 is essential for EGF induction of cell proliferation in gastric RGMI cells. Dig Dis Sci 2003, 48:2257-2262.

45. Boissel J-P, Ohly D, Bros M, Godtel-Armbrust U, Forstermann U, Frank $S$ : The neuronal nitric oxide synthase is upregulated in mouse skin repair and in response to epidermal growth factor in human HaCaT keratinocytes. J INVEST DERMATOL 2004, 123:132-139.

46. Banan A, Zhang L, Fields JZ, Farhadi A, Talmage DA, Keshavarzian A: PKC-zeta prevents oxidant-induced iNOS upregulation and protects the microtubules and gut barrier integrity. $\mathrm{Am} \mathrm{J}$ Physiol Gastrointest Liver Physiol 2002, 283:G909-G922.

47. Yang C-M, Chien C-S, Hsiao L-D, Luo S-F, Wang C-C: InterleukinIbeta-induced cyclooxygenase-2 expression is mediated through activation of p42/44 and p38 MAPKS, and NF-kappaB pathways in canine tracheal smooth muscle cells. Cell Signal 2002, | 4:899-9|I.

48. Beere HM: "The stress of dying": the role of heat shock proteins in the regulation of apoptosis. J Cell Sci 2004, I I 7:264I-265I.

49. Antonsson B, Conti F, Ciavatta A, Montessuit S, Lewis S, Martinou I, Bernasconi L, Bernard A, Mermod J], Mazzei G, Maundrell K, Gambale F, Sadoul R, Martinou JC: Inhibition of Bax channel-forming activity by Bcl-2. Science 1997, 277:370-372.

50. Donovan M, Cotter TG: Control of mitochondrial integrity by Bcl-2 family members and caspase-independent cell death. Biochim Biophys Acta 2004, 1644:133-147.

5I. Boatright KM, Salvesen GS: Mechanisms of caspase activation. Curr Opin Cell Biol 2003, 15:725-73I.

52. Beere HM, Green DR: Stress management - heat shock protein-70 and the regulation of apoptosis. Trends Cell Biol 200I, II:6-10.

53. Tepperman BL, Jacobson ED: Circulatory factors in gastric mucosal defense and repair. In Physiology of the Gastroentestinal Tract Third edition. Edited by: Johnson LR. New York: Raven Press; |994:|33|-|35|.

\section{Pre-publication history}

The pre-publication history for this paper can be accessed here:

http://www.biomedcentral.com/1471-230X/6/22/pre

pub

\section{Publish with Bio Med Central and every scientist can read your work free of charge}

"BioMed Central will be the most significant development for disseminating the results of biomedical research in our lifetime. "

Sir Paul Nurse, Cancer Research UK

Your research papers will be:

- available free of charge to the entire biomedical community

- peer reviewed and published immediately upon acceptance

- cited in PubMed and archived on PubMed Central

- yours - you keep the copyright 